\title{
É POSSÍVEL A MODULAÇÃO DE EFEITOS NAS DECISÕES ADMINISTRATIVAS?
}

\author{
IS IT POSSIBLE THE MODULATION EFFECTS ON ADMINISTRATIVES \\ DECISIONS?
}

Rafael Maia Guanaes ${ }^{1}$

\begin{abstract}
SUMÁRIO: Introdução; 1 . Histórico do déficit evolutivo da Administração Pública; 1.1. Da teoria da tripartição das funções estatais como forma de racionalizar o poder; 1.2. Das deformidades ocorridas no processo de consolidação no Brasil da teoria da separação de poderes; 1.3. A tendência transformadora do constitucionalismo e suas conseqüências no Brasil contemporâneo; 2. Formas de utilização e finalidade dos mecanismos e instrumentos decisórios pelo Poder Público; 2.1. Mecanismos e instrumentos decisórios utilizados tradicionalmente pelo executivo - ótica conservadoracorporativista; 2.2. Das possibilidades de utilização e finalidade dos mecanismos e instrumentos utilizados pelo poder público com base no paradigma do estado democrático de direito; 2.3 . Técnica de modulação de efeitos como forma de salvaguardar a segurança jurídica nas decisões administrativas; Considerações finais; Referências das fontes citadas.
\end{abstract}

RESUMO: As mudanças que atingem o direito administrativo nos tempos atuais devido à intensa busca por justiça e ética nas decisões administrativas por parte de expressivos setores da sociedade exigem do administrador público o domínio de instrumentos dispostos no ordenamento jurídico que se distanciem mais da mera expressão do braço governamental dotado de poder decisório e que aproxime a atuação de seus agentes do princípio fundamental expresso na Carta de 1988 do Estado Democrático de Direito, que possui como destinatário de suas ações administrativas o cidadão - principal prejudicado nas decisões administrativas tomadas sem observância ao princípio ético, e não o ente federativo ao qual possui relação funcional. Disponibilizar tal instrumento ao administrador público visa procurar satisfazer uma sociedade cada vez mais consciente de seu papel no exercício da cidadania e ávida pela solução de

\footnotetext{
1 Especialista em Direito Público pela Universidade de Brasília (UnB). Procurador Federal com lotação na cidade do Rio de Janeiro/RJ. E-mail: rafael.guanaes@ig.com.br
} 
GUANAES, Rafael Maia. É possível a modulação de efeitos nas decisões administrativas?. Revista Eletrônica Direito e Política, Programa de Pós-Graduação Stricto Sensu em Ciência Jurídica da UNIVALI, Itajaí, v.10, n.2, 10 quadrimestre de 2015. Disponível em: www.univali.br/direitoepolitica - ISSN 1980-7791.

demandas às quais o Estado tem o dever constitucional de atender no limite de suas possibilidades técnicas.

Palavra-chave: Direito Administrativo; Constitucionalização; Agentes Públicos; Estado Democrático de Direito.

ABSTRACT: The changes affecting the administrative law in modern times due to the search for justice and ethics in management decisions by significant sectors of society require the public domain administrator the willing instruments in the legal system to distance themselves more than a expression the government arm endowed with decision-making power and that approximates the performance of its agents of the fundamental principle expressed in the 1988 State of Law Constitution operating as a recipient of its administrative actions citizens - most harmed in the administrative decisions taken without regard to the principle ethical, and not the federal entity which has functional relationship. Provide such an instrument to the public administrator aims to seek to satisfy an increase the conscious of their role in society citizenship and eager for demands solution to which the state has a constitutional duty to meet the limit of its technical possibilities.

Keywords: Administrative Law; Constitutionalisation; Public Officials; State of Law.

\section{INTRODUÇÃO}

Dentro de um cenário "a se construir" com o advento do Estado Democrático de Direito decorrente das profundas mudanças de cunho fortemente democrático contidas na Carta Magna de 1988, o direito administrativo se torna sem quaisquer sombras de dúvidas como uma das disciplinas onde mais se possui campo para atuação da comunidade científica dentro do Direito, tendo em vista que a forte carga autoritária existente à época do regime militar implantado não só no Brasil como em boa parte da América Latina se expressou com grande vigor nesta disciplina do Direito, por ser simplesmente um dos principais canais utilizados por governos autoritários para disseminar seus ideais de natureza totalitária dentro da comunidade jurídica.

O que se deseja instigar com este estudo é a possibilidade de se adotar o respeito a direitos adquiridos mesmo em se tratando de atos administrativos nulos de pleno direito quando declarados pela Administração no exercício de seu 
GUANAES, Rafael Maia. É possível a modulação de efeitos nas decisões administrativas?. Revista Eletrônica Direito e Política, Programa de Pós-Graduação Stricto Sensu em Ciência Jurídica da UNIVALI, Itajaí, v.10, n.2, $1^{\circ}$ quadrimestre de 2015. Disponível em: www.univali.br/direitoepolitica - ISSN 1980-7791.

poder de autotutela, posto que tanto na aplicação da interpretação lógicosistemática da Súmula 473 como no entendimento doutrinário adotado à época sobre o assunto, o escopo do enunciado sumulado visava fulminar qualquer efeito jurídico ao ato administrativo nulo.

Com efeito, a interpretação realizada pela doutrina divide em duas partes o enunciado. A primeira parte versaria sobre a anulação do ato administrativo e a segunda sobre o instituto da revogação. Deixe-se bem claro que o objetivo do presente estudo não está em tecer críticas a tal divisão. Ela se mostra correta e se coaduna com a intenção da composição da Corte Suprema à época, porém nos dias de hoje ela merece uma releitura para se adequar à forte influência dos princípios constitucionais de natureza ética como a transparência, moralidade administrativa e a proporcionalidade em sentido estrito.

A conseqüência jurídica desta regra trazia a impossibilidade de discussão na via administrativa sobre a manutenção dos efeitos deste ato, isso no campo jurídico porque no campo fático a Administração inevitavelmente tinha que enfrentar essa questão de forma extremamente precarizada, pois, sem qualquer regulamentação legal a respeito e pela natureza vinculada do exercício da função pública, não restaria outra alternativa ao agente público senão a de negar qualquer direito aos particulares que demande tal pretensão pela via administrativa.

Com o surgimento de um Judiciário que após a Constituição Cidadã passa a atuar de forma horizontalizada, fortemente influenciado pelos postulados de acesso à Justiça como podemos vislumbrar por exemplo na adesão por parte do Constituinte à teoria das ondas renovatórias estipuladas pelos juristas Mauro Capelleti e Bryant Garth na célebre obra sobre o tema²:

O recente despertar de interesse em torno do acesso efetivo à Justiça levou a três posições básicas, pelo menos nos países do mundo Ocidental. Tendo início em 1965, estes posicionamentos emergiram mais ou menos em seqüência cronológica. Podemos afirmar que a primeira solução para o

\footnotetext{
2 CAPPELLETTI, Mauro; GARTH, Bryant. Acesso à Justiça. Tradução de Ellen Gracie Northfleet.
} Porto Alegre: Sergio Antonio Fabris, 1988, p. 31 
GUANAES, Rafael Maia. É possível a modulação de efeitos nas decisões administrativas?. Revista Eletrônica Direito e Política, Programa de Pós-Graduação Stricto Sensu em Ciência Jurídica da UNIVALI, Itajaí, v.10, n.2, $1^{0}$ quadrimestre de 2015. Disponível em: www.univali.br/direitoepolitica - ISSN 1980-7791.

\begin{abstract}
acesso - a primeira 'onda' desse movimento novo - foi a assistência judiciária; a segunda dizia respeito às reformas tendentes a proporcionar representação jurídica para os interesses 'difusos', especialmente nas áreas de proteção ambiental e do consumidor; e o terceiro - e mais recente - é o que nos propomos a chamar simplesmente "enfoque de acesso à Justiça" porque inclui os posicionamentos anteriores, mas vai muito além deles, representando, dessa forma, uma tentativa de atacar as barreiras ao acesso de modo mais articulado e compreensivo.
\end{abstract}

Garantindo-se dessa maneira proteção a grupos sociais alvejados há décadas pela "crise material da sociedade" ${ }^{3}$ que assola os países em desenvolvimento, como é o caso brasileiro, fazendo surgir dentro deste cenário de correção de um déficit histórico de prestação jurisdicional o assoberbamento de diversas demandas que o antigo regime de natureza autoritária impedia de apreciação por meio da força do poder político, e dentre essas pretensões de um Estado apto e compromissado constitucionalmente a sedimentar suas bases de legitimidade democrática encontramos a preservação de direitos adquiridos em face de atos administrativos declarados nulos pela Administração.

Como resposta à modalidade de pedido levado à apreciação exposto supra, o Poder Judiciário demonstrou em seus julgados consonância com o movimento do pós-positivismo e da normatividade dos princípios jurídicos ${ }^{4}$, acatando pedidos dessa natureza sob o fundamento de que ou pelo princípio de segurança nas relações jurídicas ou por boa-fé se faz necessária a mitigação dos conceitos de completude do ordenamento jurídico, ou seja, da possibilidade deste esgotar por completo toda e qualquer possibilidade a ser avistada no plano fático e o de formalismo para se formatar dentro do ordenamento a possibilidade de se criar um espaço de tempo que assegure a sobrevivência provisória da lei que se revela incompatível com a Constituição.

\footnotetext{
${ }^{3}$ BONAVIDES, Paulo. Curso de Direito Constitucional, São Paulo,Ed. Malheiros, 2007, p. 487

4 Conceituação didática sobre o movimento do pós-positivismo: BARROSO, Luis Roberto. Fundamentos teóricos e filosóficos do novo constitucionalismo brasileiro (Pósmodernidade, teoria crítica e pós-positivismo) In Revista Diálogo Jurídico, Salvador, CAJ Centro de Atualização Jurídica, v. 1, n 6, setembro de 2001, p. 19
} 
GUANAES, Rafael Maia. É possível a modulação de efeitos nas decisões administrativas?. Revista Eletrônica Direito e Política, Programa de Pós-Graduação Stricto Sensu em Ciência Jurídica da UNIVALI, Itajaí, v.10, n.2, $1^{\circ}$ quadrimestre de 2015. Disponível em: www.univali.br/direitoepolitica - ISSN 1980-7791.

Atente-se para a terminologia adotada para se classificar a relação de adequação da lei ou ato normativo nesses casos, podendo ser apresentada como uma forma de flexibilização da técnica de controle de constitucionalidade de lei que se apresenta como incompatível perante a ordem jurídica (lei ainda constitucional), deixando de ser taxada como norma inconstitucional por motivos fáticos em determinado momento histórico, indo contra tradicional posicionamento da doutrina constitucional de imediata retirada da norma inconstitucional após sua declaração na via judicial ${ }^{5}$.

Desta forma vimos sem sombra de dúvidas que a Administração Pública, no atual estágio de desenvolvimento do Estado Brasileiro, seguindo adequadamente as diretrizes da nova hermenêutica constitucional conforme fundamentos a serem melhor delineados mais à frente, poderia com plena legitimidade constitucional se utilizar do mecanismo da modulação de efeitos em suas decisões, instituído na legislação brasileira pelo art. 27 da Lei 9868/99 nas decisões proferidas pelo Supremo Tribunal Federal quando este órgão atua como o competente para realizar o controle de constitucionalidade de leis.

\section{HISTÓRICO DO DÉficit EVOLUTIVO DA ADMINISTRAÇÃo PÚBLICA FEDERAL}

\subsection{Da teoria da tripartição das funções estatais como forma de racionalizar o poder}

A divisão de funções do poder estatal tem as suas raízes nos ensinamentos de Aristóteles, que em seu famoso "Tratado de Política", fixou de forma objetiva a tripartição que vemos utilizada até os dias atuais ${ }^{6}$, entre Poder deliberativo (atual legislativo), Poder Executivo e Poder Judiciário.

O primeiro destes três poderes é o que delibera sobre os negócios do Estado. O segundo compreende todas as

\footnotetext{
${ }^{5}$ BUZAID, Alfredo. Da Ação Direta de Inconstitucionalidade no Direito Brasileiro. São Paulo, Ed. Saraiva, p. 132

${ }^{6}$ ARISTÓTELES, Tratado de política, São Paulo, Nova Cultural, 2000, p. 206
} 
GUANAES, Rafael Maia. É possível a modulação de efeitos nas decisões administrativas?. Revista Eletrônica Direito e Política, Programa de Pós-Graduação Stricto Sensu em Ciência Jurídica da UNIVALI, Itajaí, v.10, n.2, $1^{\circ}$ quadrimestre de 2015. Disponível em: www.univali.br/direitoepolitica - ISSN 1980-7791.

magistraturas ou poderes constituídos, ou seja, aqueles de que o Estado tem necessidade para agir, as suas atribuições e a maneira de as realizar. O terceiro abrange as tarefas de jurisdição.

Verifica-se com facilidade na obra de Aristóteles uma visão de que, nesta partilha, o Poder deliberativo exerce uma posição de prevalência sobre os outros. Essa possibilidade externada nas entrelinhas pelo pensador grego pode ser considerada como praticamente inevitável dentro do processo evolutivo da separação de poderes.

Os trabalhos deste autor sobre as práticas políticas e sua conformação vem sofrer críticas no século XVIII e XIX por pensadores franceses do movimento iluminista, especialmente pelo Barão de Montesquieu, trazidos na obra "O Espírito das leis"7.

A confusão de Aristóteles aparece claramente quando ele trata da monarquia. Estabelece cinco espécies e não as diferencia pela forma de constituição mas pelas coisas acidentais, como as virtudes os vícios do príncipe, ou pelas coisas estranhas, como a usurpação da tirania ou a sucessão da tirania. Aristóteles coloca na classe das monarquias o império dos persas e o reino da Lacerdônia. Mas quem não vê que era um Estado despótico e outro uma república? Os antigos, que não conheciam a divisão dos três poderes no governo de um só, não podiam ter uma idéia correta da monarquia.

Convém mencionar que o autor francês não fazia parte da classe social ascendente à época, a burguesia, assim como não se pode concluir que aderia ao movimento liberal, pois se tratava de um detentor de um baronato, sendo um típico membro da nobreza francesa. O que ele faz com sua célebre obra é externar um pensamento crítico ao absolutismo, propondo dessa forma uma divisão de poderes visando uma melhor equalização na distribuição de força

\footnotetext{
7 MONTESQUIEU, Charles Louis de Secondat, Baron de la. O Espírito das Leis, Trad. Fernando Henrique Cardoso e Leôncio Martins Rodrigues, São Paulo, Abril Cultural, Livro II, 1979, p. 155
} 
GUANAES, Rafael Maia. É possível a modulação de efeitos nas decisões administrativas?. Revista Eletrônica Direito e Política, Programa de Pós-Graduação Stricto Sensu em Ciência Jurídica da UNIVALI, Itajaí, v.10, n.2, $1^{\circ}$ quadrimestre de 2015. Disponível em: www.univali.br/direitoepolitica - ISSN 1980-7791.

entre os detentores do poder, como bem salienta Cardoso ${ }^{8}$ "Conservador por temperamento e condição social, esteve sempre a serviço de sua classe."

Todavia, a relação instituída entre o autor e sua obra se assemelham ao vínculo entre o criador e criatura. No momento em que o fruto de sua inspiração sai de sua esfera de disponibilidade, ele não possui o controle sobre os terrenos em que suas idéias irão semear. É o mesmo fato que pode ser verificado na definição realizada por Paulo Bonavides da escola objetivista de interpretação da lei, em que 0 ato normativo, no momento em que é publicado, tem-se consolidada sua autonomia em relação ao autor da disposição normativa, amoldando-se em sua totalidade ao sistema jurídico ${ }^{9}$. E pode-se falar que foi o que aconteceu com a obra do ilustre barão francês.

\subsection{Das deformidades ocorridas no processo de consolidação no Brasil da teoria da separação de poderes}

Essa capacidade de se manejar essa engenhosa teoria dos três poderes estatais de forma abusiva como processo legitimante da estrutura de poder foi extremamente utilizada em terra brasilis. Convém frisar que essa possibilidade de se tentar afastar o povo do processo decisório da vida política de forma alguma foi afastada pelos teóricos liberais ${ }^{10}$ "Todos os cidadãos, nos diversos distritos, devem ter direito a dar seu voto para escolher o representante, exceto os que estão em tal estado de baixeza, que são considerados sem vontade própria.", tendo em vista que visavam abordar como direitos praticamente absolutos os referentes às liberdades civis e ao direito de propriedade, constatando inegavelmente que atuavam para servir à sua classe, o que reflete completa falta de compromisso com qualquer forma de transformação social ou econômica.

\footnotetext{
${ }^{8}$ CARDOSO, Fernando Henrique, Introdução. In MONTESQUIEU, Charles Louis de Secondat, Baron de la. O Espírito das Leis, Trad. Fernando Henrique Cardoso e Leôncio Martins Rodrigues, São Paulo, Abril Cultural, Livro II, 1979, p. 19

${ }^{9}$ BONAVIDES, Paulo. Curso de Direito Constitucional, São Paulo ,Ed. Malheiros, 2007, p. 454

10 MONTESQUIEU, Charles Louis de Secondat, Baron de la. O Espírito das Leis, Trad. Fernando Henrique Cardoso e Leôncio Martins Rodrigues, São Paulo, Abril Cultural, Livro II, 1979, p. 150.
} 
GUANAES, Rafael Maia. É possível a modulação de efeitos nas decisões administrativas?. Revista Eletrônica Direito e Política, Programa de Pós-Graduação Stricto Sensu em Ciência Jurídica da UNIVALI, Itajaí, v.10, n.2, $1^{\circ}$ quadrimestre de 2015. Disponível em: www.univali.br/direitoepolitica - ISSN 1980-7791.

Buscando socorro na história do Brasil, concordamos com Victor Nunes Leal ${ }^{11}$, que coloca com exatidão a existência de relações de caráter nitidamente promíscuo entre o poder político e o poder econômico dominante com vistas a enfraquecer a relação Estado-Sociedade.

Portanto, a falta de quadros técnicos ocupando postos de extrema relevância na Administração por várias gerações - aliada à ausência de critérios (i) tanto no processo de ingresso desses "apadrinhados políticos" (ii) quanto no momento em que estes indivíduos estão no comando da gestão pública cometendo os mais diversos tipos de aberrações no exercício do poder político - podem servir de motivos históricos para que até os dias atuais países como o Brasil estejam em uma condição mencionada na feliz expressão cunhada pelos constitucionalista Lênio Streck como "Países de Modernidade Tardia", que necessitam inevitavelmente de uma Teoria da Constituição adequada para o preenchimento do pesado déficit histórico em matéria de compromissos e realizações próprias da democracia, exigindo da Constituição Brasileira uma forte carga de dirigismo e um papel mais intervencionista da jurisdição constitucional, o que afeta de forma significativa o equilíbrio da tripartição de poderes em sua concepção clássica ${ }^{12}$.

\subsection{A tendência transformadora do constitucionalismo e suas consequências no Brasil contemporâneo}

A Constituição democrática de 1988 demandou uma verdadeira mudança paradigmática no exercício da hermenêutica jurídica. Nessa linha de pensamento, os valores atinentes ao exercício da cidadania e aos mecanismos de garantia constitucionais contra abusos de poder cometidos por autoridades públicas não podem ser considerados aqueles que prevaleciam antes da promulgação da Carta Magna. A inserção de numerosos valores sociais

${ }^{11}$ LEAL, Victor Nunes, Coronelismo, enxada e voto: o município e o sistema representativo na Brasil, São Paulo, Alfa Omega, 1975, p. 40

12 STRECK, Lênio Luiz, O Papel da Jurisdição Constitucional na realização dos direitos sociaisfundamentais, In Direitos Fundamentais sociais: Estudos de Direito Constitucional, Internacional e Comparado, Renovar, 2003, p. 170 
GUANAES, Rafael Maia. É possível a modulação de efeitos nas decisões administrativas?. Revista Eletrônica Direito e Política, Programa de Pós-Graduação Stricto Sensu em Ciência Jurídica da UNIVALI, Itajaí, v.10, n.2, $1^{\circ}$ quadrimestre de 2015. Disponível em: www.univali.br/direitoepolitica - ISSN 1980-7791.

expressamente consignados, somado ao fato de a Carta Política estipular diretrizes a serem buscadas visando à consolidação da Democracia e do Estado Democrático de Direito estabelecem verdadeiro vínculo entre os agentes públicos no exercício das funções estatais, tendo em vista a realização dos direitos fundamentais.

Ressalte-se que tal mister não deve caber somente ao legislador, conforme boa doutrina defende ${ }^{13}$, sob pena de se deixar todo o árduo sacerdócio de luta pelo amadurecimento do Estado Democrático de Direito no Estado Brasileiro nas mãos únicas do Legislativo, dando margem assim a uma interpretação restritiva que não se revela adequada no atual contexto histórico. Nesse sentido a doutrina da sociedade aberta de intérpretes da Constituição, construída pelo ilustre Professor Doutor Honoris Causa pela Universidade de Brasília (UnB) Peter Häberle, que em breve definição que será melhor vista no decorrer do trabalho, trata de democratizar o processo de interpretação constitucional, inserindo no círculo de intérpretes da Carta Fundamental todos os cidadãos e grupos sociais que vivem a Constituição ${ }^{14}$.

Uma das mais significativas características do constitucionalismo na sociedade contemporânea é a filtragem da própria política ${ }^{15}$, que hoje não se encontra mais exercitada de forma ilimitada.

Cumpre destacar que a estipulação de direitos fundamentais e garantia das liberdades em uma Constituição busca assegurar uma dupla função: (i) conferir estabilidade e segurança nas relações sociais, mostrando-se resistente às alternâncias de poder dentro de uma democracia, e, ao mesmo tempo, (ii) atuar como limitador dos poderes estatais.

\footnotetext{
${ }^{13}$ STRECK, Lênio Luiz, In Direitos Fundamentais e Novos Direitos, $2^{a}$ série, Rio de Janeiro, Lumen Juris, 2006, p. 01

14 HÄBERLE, Peter. Hermenêutica Constitucional. A sociedade aberta de intérpretes da Constituição: contribuição para a interpretação pluralista e "procedimental" da Constituição, Traduzido por Gilmar Ferreira Mendes, Sergio Antonio Fabris Editor, Porto Alegre, reimpressão, 2002, p. 34

${ }^{15}$ BERCOVICI, Gilberto, In Canotilho e a Constituição Dirigente, organizado por Jacinto Nelson de Miranda Coutinho, Rio de Janeiro, Renovar, 2005, p. 78
} 
GUANAES, Rafael Maia. É possível a modulação de efeitos nas decisões administrativas?. Revista Eletrônica Direito e Política, Programa de Pós-Graduação Stricto Sensu em Ciência Jurídica da UNIVALI, Itajaí, v.10, n.2, $1^{0}$ quadrimestre de 2015. Disponível em: www.univali.br/direitoepolitica - ISSN 1980-7791.

Nesse contexto, convive-se com uma intensa problematização de como o antigo Estado soberano deverá se relacionar com o povo, agora soberano ${ }^{16}$, fonte legítima de poder no Estado Moderno. Esse problema pode ser resumido em questão como a seguinte: como se pode conceber um Estado que somente detinha a função de arrecadar e custear a aristocracia e que, na modernidade, deve atuar como protetor das liberdades públicas e como instrumento de satisfação dos membros da comunidade?

Pode-se colocar que essa realidade pode ser um belo sinal de assimilação do sentimento constitucional, pelo menos por parte dos agentes estatais, o que denota maturação no processo de desenvolvimento de diminuição do abismo colocado pelas forças antidemocráticas entre normatividade e normalidade, conforme visto nas lições de Smend ${ }^{17}$. Esse novo paradigma leva a perceber que a Constituição passa a ter forte carga substantiva, indo além de sua típica natureza formal por se tratar de documento escrito e instituidor de um instrumento de garantias dos direitos fundamentais frente o Estado e a outros indivíduos, não sendo apenas uma mera Carta de Direitos.

Mas ainda falta dar alguns importantes passos para se falar da existência do Estado Democrático de Direito em sua plenitude em solo brasileiro. Papel esse que o jurista passa a ter mais por um compromisso cultural de salvar sua identidade no exercício de sua nova função social que a sociedade

\footnotetext{
${ }^{16}$ LEAL, Rogério Gesta, O Estado-Juiz na Democracia Contemporânea, Porto Alegre, Livraria do Advogado, 2007, p. 78

17 VERDÚ, Pablo Lucas, O sentimento constitucional, Rio de Janeiro, Editora Forense, $1^{\text {a }}$ edição, 2004. Sobre o binômio normatividade-normalidade: " (...) En particular debe tenerse presente la poderosa teoría que Heller construye en torno a la relación entre norma e normalidad: "Así como no pueden estimarse completamente separados lo dinámico y lo estático, tampoco pueden serlo la normalidad y la normatividad, el ser y el deber ser em el concepto de La Constitución". Dentro de esa misma idea se incluyen los factores culturales que, como es obvio, forman parte de la realidad (o normalidad). Heller formula así su conocida distinción entre Constitucion normada y no normada. Esta última es la Constitucion real, que puede consistir em una normalidad sin normatividad, pero lo contrario no es posible. La Constitución normada a su vez puede serlo jurídicamente y extrajurídicamente (por la costumbre, la moral, la urbanidad, la moda, por ejemplo). Las implicaciones democráticas de las tesis de Heller son claras: La normalidad (lo que ocurre), ha de coincidir com la normatividad (lo que debe ocurrir). Heller formulo esta tesis en 1934 y, seis años después, Mortati (por ejemplo) aludió a la relación entre normalidad y normatividad, peró no intentó examinar las implicaciones profundas de esa relación porque lá habría sido imposible fundamentar, por esa via, las bases constitucionales del Estado fascista. (...)" HÄBERLE, Peter, El estado constitucional, Obtido via internet.
} http://www.bibliojuridica.org/libros/1/14/2.pdf, 03/03/2010, 23:30 
GUANAES, Rafael Maia. É possível a modulação de efeitos nas decisões administrativas?. Revista Eletrônica Direito e Política, Programa de Pós-Graduação Stricto Sensu em Ciência Jurídica da UNIVALI, Itajaí, v.10, n.2, $1^{0}$ quadrimestre de 2015. Disponível em: www.univali.br/direitoepolitica - ISSN 1980-7791.

contemporânea exigiu do que por defesa de algum ideal, pois temos nas firmes palavras do Professor italiano Paolo Grossi um verdadeiro estado de sonolência que vive o jurista há pelo menos duzentos anos, em que se via em uma posição de profunda submissão frente ao Estado, que de forma peremptória enunciava verdades absolutas, em que somente cabia ao jurista se sujeitar aos destinos traçados pelo Poder Público ${ }^{18}$.

Há duzentos anos - e em boa parte ainda hoje, malgrado a percepção de algumas consciências vivas e culturalmente vigilantes durante o decorrer no século $X X$ - o jurista viveu e vive docilmente o papel que Ihe foi destinado pelo poder político, completamente inclinado a um breviário de verdades indiscutíveis esculpidas por aquele poder por meio de um de tipo tábua sagrada de Moisés: o Estado, como representante e intérprete da vontade popular, com o conseqüente corolário do primado da lei como voz do Estado e obviamente como manifestação genuína da vontade geral; rigidíssimo princípio da legalidade; o extremamente rígido e efetivado princípio da divisão dos poderes, com a absoluta reserva ao poder legislativo (isto é, político) da produção do direito.

Não existem incoerências nessa construção, que se assemelha a um teorema de geometria nas suas linhas perfeitas. Tudo torna perfeitamente, se não fosse por aquele axioma de fundo, que tudo sustenta e que reveste o caráter da suprema ficção a apoiar uma atenta estratégia política: a identificação entre Estado e sociedade civil, a identificação do conteúdo da lei na vontade geral. Suprema ficção porque nunca o Estado é capaz de exprimir toda a complexidade e riqueza da sociedade, ainda menos um Estado monoclassista e extremamente elitista como aquele saído da revolução burguesa de 89 , tão longe dos interesses e das necessidades das massas populares quanto a velha monarquia do antigo regime.

Com relação ao direito humanitário, ele possui forte ligação com as Constituições democráticas, sendo estas as responsáveis por instituírem núcleos básicos invioláveis por qualquer variante, seja externa ou do próprio sistema jurídico, garantias estas consolidadas como verdadeiras vitórias históricas dos cidadãos,

18 GROSSI, Paolo. A formação do jurista e a exigência de um hodierno "repensamento" epistemológico. Obtida via internet. ojs.c3sl.ufpr.br/ojs2/index.php/direito/article/download/1731/1431, 15/03/2010, 02:30 
GUANAES, Rafael Maia. É possível a modulação de efeitos nas decisões administrativas?. Revista Eletrônica Direito e Política, Programa de Pós-Graduação Stricto Sensu em Ciência Jurídica da UNIVALI, Itajaí, v.10, n.2, $1^{\circ}$ quadrimestre de 2015. Disponível em: www.univali.br/direitoepolitica - ISSN 1980-7791.

que com o passar do tempo e com o constante aumento de demandas da pauta reivindicatória por parte dos grupamentos sociais, se vai formando um valioso patrimônio da coletividade e a sua defesa pode ser exercida face a terceiros, seja ou o particular ou o Poder Público, seja de que esfera governamental for.

\section{FORMAS DE UTILIZAÇÃO E FINALIDADE DOS MECANISMOS E INSTRUMENTOS DECISÓRIOS PELO PODER PÚBLICO}

\subsection{Mecanismos e instrumentos decisórios utilizados tradicionalmente pelo executivo - ótica conservadora-corporativista ${ }^{29}$}

Reputamos como extremamente precisa a citação de J.J. Gomes Canotilho para qualificar a programaticidade da Constituição Portuguesa de 1933 e da Constituição Brasileira de 1946 quando o autor situa o leitor temporalmente essas Cartas com o cenário político à época, de índole autoritária e sob o comando de rígidas ditaduras militares, especialmente quando menciona que tanto a Constituição Portuguesa de 1976 como a Brasileira de 1988 visavam antes de tudo tentar inserir um programa emancipatório em um cenário de grande problematização de socialidade constitucional e de defesa de juridicidade estatal, momento em que se nutriu um sentimento de crença na força transformadora das normas constitucionais, numa tentativa de se reaver por parte da sociedade de parcela das forças de poder, nesse momento estando praticamente em sua totalidade nas mãos do Estado.

Esse enclausuramento político da Administração decorrente do autoritarismo imposto somado à uma cultura de tomada de decisões por motivos de natureza discricionária, em que os gestores da coisa pública não possuíam grandes preocupações com os bens jurídicos tutelados pelo ordenamento jurídico, se atendo restritamente à literalidade da lei que levou à conclusão da qual concordamos com D. de F. Moreira Neto, no sentido de que o que se verificou no Direito Administrativo foi uma "evolução divergente" ${ }^{19}$, com a Administração

\footnotetext{
${ }^{19}$ MOREIRA NETO, Diogo de Figueiredo, Mutações de Direito Administrativo, Rio de Janeiro,
} Renovar, 2001, p. 11 
GUANAES, Rafael Maia. É possível a modulação de efeitos nas decisões administrativas?. Revista Eletrônica Direito e Política, Programa de Pós-Graduação Stricto Sensu em Ciência Jurídica da UNIVALI, Itajaí, v.10, n.2, $1^{\circ}$ quadrimestre de 2015. Disponível em: www.univali.br/direitoepolitica - ISSN 1980-7791.

Pública se tornando o ramo mais conservador do Estado e o que mais se beneficiou do fenômeno da hipertrofia estatal no século $X X$, fazendo com que conquistas históricas de natureza humanitária obtidas ao longo de décadas e muito suor e sangue sejam usufruídas de forma bastante demorada e dolorida por grande parte da população brasileira.

Uma das formas de se verificar essa triste realidade pode ser retratada na aplicação da velha hermenêutica no momento de análise do caso concreto trazido à apreciação pela Administração, em que conhecidos conceitos abertos como por exemplo o de interesse público, em que se extrai das idéias centrais desse instituto por não raras vezes a existência de um interesse próprio da pessoa estatal, externo e contraposto aos dos cidadãos ${ }^{20}$.

$\mathrm{Na}$ defesa de ultrapassados e descabidos dogmas como o de princípio de autoridade aplicado como embasamento do desempenho de suas funções e pela prática de suas condutas, o administrador público dentro da tripartição dos poderes estatais se posiciona muito distante do legislador, dado o intenso processo de interação e comunicação com diversos setores significativos da sociedade. E ainda mais longe a Administração se encontra do Judiciário, sendo esta esfera de Poder sem sombra de dúvidas a que mais evoluiu no espaço político dentro das democracias contemporâneas, se consolidando como poder independente para se fazer o papel de guardião da Constituição face às ações do poder político no sentido de tentar desestabilizá-la.

E não se pode deixar de se fazer registro que esse Poder há não muito tempo atrás possuía uma cultura em que o Juiz se apresentava no papel de ser a pessoa que sozinha, através apenas de sua técnica e das regras de experiência seria capaz de pronunciar um julgamento sem qualquer resquício de falha ou de erro e que não se iria recorrer de suas decisões por se tratar de uma ofensa ao prolator da decisão. Esse posicionamento foi também abordado pelos teóricos da nova hermenêutica, mais precisamente Ronald Dworkin.

${ }^{20}$ ALLEGRETTI, Umberto, Amministrazione Pubblica e Constituzione, Padova, CEDAM, 1996, p. 04 
GUANAES, Rafael Maia. É possível a modulação de efeitos nas decisões administrativas?. Revista Eletrônica Direito e Política, Programa de Pós-Graduação Stricto Sensu em Ciência Jurídica da UNIVALI, Itajaí, v.10, n.2, $1^{\circ}$ quadrimestre de 2015. Disponível em: www.univali.br/direitoepolitica - ISSN 1980-7791.

Porém temos como pertinente a crítica de Habermas sobre tal posicionamento, que, citando a figura da mitologia grega do herói Hércules expõe a falibilidade de tal premissa, posto que para se cumprir a tarefa de conhecer a totalidade dos princípios e diretrizes políticas do ordenamento jurídico e um panorama completo da densa rede de argumentos trançados que vinculam os elementos do direito vigente somente uma pessoa que possua uma capacidade intelectual comparável à força física de Hércules ${ }^{21}$ para desempenhar a contento tal missão, pois deveria possuir um conhecimento ideal inimaginável para o ser humano.

Diante dessa realidade em que se imperava o arbítrio, passa-se a refletir dentro da comunidade sociológica e jurídica sobre de que vale a Constituição como instrumento conformador da ordem jurídica se as forças de poder que legitimam as diretrizes mestras expostas nessas Cartas Fundamentais não conseguem expor e ver aplicadas dentro da comunidade seus anseios e suas demandas? Conclui-se dessa análise que esse tipo de Constituição em verdade não traz como seu propósito expressar os projetos que envolvam Estado e Sociedade de forma harmônica e dinâmica, ciente de que as acomodações como solução política não podem ser admitidas e muito menos ignoradas ou reprimidas, vemos na lição de Ferdinand Lassale que em cartas autoritárias se enxerga com clareza um conflito entre Constituição escrita e Constituição real e que enquanto não se vislumbra alternativas para resolver esse impasse a Constituição cumpre o destino trágico de ser mera folha de papel, de forma que os problemas constitucionais não são problemas de direito, mas problemas de poder ${ }^{22}$.

A Constituição dentro do sistema pós-moderno possui a característica de incorporar novas dimensões do texto constitucional de forma contínua como também os problemas e angústias inter-geracionais, constituindo assim um extremado dinamismo que somado à velocidade de profusão de informações originada pelo inevitável processo de globalização dos setores de produção. Portanto, temos como uma das mais importantes funções da atual Constituição a

\footnotetext{
${ }^{21}$ HABERMAS, Jürgen, Between Facts and Norms. Contribution to a Discurse Theory of Law and Democracy, tradução de William Rehg, Cambridge, Massachussets Institute of Tecnology Press, 1996, p.132.

${ }^{22}$ LASSALE, Ferdinand, A essência da Constituição. Tradução de Walter Stöner, $2^{a}$ Ed., Rio de Janeiro, Liber Juris, p. 49
} 
GUANAES, Rafael Maia. É possível a modulação de efeitos nas decisões administrativas?. Revista Eletrônica Direito e Política, Programa de Pós-Graduação Stricto Sensu em Ciência Jurídica da UNIVALI, Itajaí, v.10, n.2, $1^{\circ}$ quadrimestre de 2015. Disponível em: www.univali.br/direitoepolitica - ISSN 1980-7791.

de tentar criar um complexo de garantias de direitos fundamentais conquistados ao longo do tempo e ao mesmo tempo de desconstruir determinados paradigmas estruturantes da lógica liberal-clássica, fugindo assim da idéia constitucional de ser um conjunto de verdades imutáveis, totalmente resistentes à ação do tempo.

\subsection{Das possibilidades de utilização e finalidade dos mecanismos e instrumentos utilizados pelo poder público com base no paradigma do estado democrático de direito}

Podemos verificar na bibliografia do professor alemão Peter Häberle diversos elementos que servem de paradigma no Estado Democrático de Direito aptos a justificar a aplicação da modulação de efeitos para as decisões administrativas. Este autor, sem sombra de dúvidas, vem se mostrar em perfunctória análise evolutiva da jurisprudência do Supremo Tribunal Federal (STF) como um dos maiores responsáveis da inserção e consolidação da jurisdição constitucional no Brasil, haja vista a enorme influência de suas idéias postas explícita ou implicitamente nos julgados da Corte Suprema.

De início, a concepção da Constituição como um fenômeno científico-cultural, alvo de obra específica do mestre da Universidade de Bayreuth ${ }^{23}$, em que aborda de forma inovadora na forma analítica das Constituições democráticas contemporâneas a constatação de afinidade com a criatividade cultural constituída pluralisticamente existente em determinado momento histórico, iniciando assim uma relação entre Constituição e cultura.

Relacionando tais conceitos com a realidade jurídica atual vivida em solo brasileiro, vemos com entusiasmo no estudo da jurisprudência do STF a existência de julgado no sentido de admitir a modulação de efeitos prospectivos às decisões proferidas pela Corte em sede de controle difuso, expressado exatamente em 2004, no julgado da lavra do Min. Maurício Corrêa, em composição colegiada completamente diversa da existente hoje.

${ }^{23}$ HÄBERLE, Peter. Teoria de la Constitucion como ciência de la cultura. Tradução de Emilio Mikunda. Madrid, Tecnos, 2000 
GUANAES, Rafael Maia. É possível a modulação de efeitos nas decisões administrativas?. Revista Eletrônica Direito e Política, Programa de Pós-Graduação Stricto Sensu em Ciência Jurídica da UNIVALI, Itajaí, v.10, n.2, $1^{\circ}$ quadrimestre de 2015. Disponível em: www.univali.br/direitoepolitica - ISSN 1980-7791.

Já a nova composição da Corte (Era Lula) também externou adesão à modulação de efeitos no controle difuso. De forma expressa temos Ministros de extrema influência dentro das composições da Colenda Corte, quais sejam, os Ministros Celso de Mello $^{24}$ e Ricardo Lewandowski ${ }^{25}$ que com votos muito bem fundamentados defenderam de forma combativa a tese da modulação. Porém conforme leitura do inteiro teor do leading case 353657/PR se verifica na certidão de julgamento do feito, especialmente na seção "extrato da ata", atestase o fato de que restou necessário o ingresso da Presidente da Corte à época, Min. Ellen Gracie para a votação no feito, tendo em vista a configuração do incidente do voto de Minerva para se resolver a questão de ordem levantada pelo Min. Lewandowski ${ }^{26}$.

A importância de trazermos o pronunciamento do STF a respeito da possibilidade de se estipular efeitos prospectivos às decisões na mais alta Corte do País não se esgota nas conclusões trazidas por seus membros, mas sim demonstrar que pode ser plenamente viável juridicamente essa possibilidade de se aplicar tal técnica às decisões administrativas. Correto se mostra o raciocínio de que dentro do Estado Democrático de Direito não se admite mais argumentos de autoridade como fundamento teórico para a construção de teses jurídicas, principalmente quando praticados por agentes do Estado no exercício de suas funções. Até porque a Colenda Corte para chegar à conclusão de não admissão da modulação de efeitos teve que ir à última etapa de julgamento, sendo necessária a intervenção do voto de Minerva para se resolver o imbroglio.

Vale destacar sobre a relação de adequação sobre o objeto do processo leading case em que se abordou a questão dos efeitos prospectivos e a forma como que esses efeitos seriam incididos. O processo tratava, em brevíssimas linhas, de recurso da União de decisão que autorizava o creditamento de IPI sobre insumo

${ }^{24}$ BRASIL, STF, ED no RE 592148/MG, Rel. Min. Celso de Mello, $2^{a} \mathrm{~T}$, publicado em DJU de $11 / 09 / 2009$

25 BRASIL, STF, RE 353657/PR, Rel. Min. Marco Aurélio, Plenário, publicado em DJU de 07/03/2008

${ }^{26}$ Note-se que não há referência expressa na certidão de julgamento apontando os Ministros que defenderam a tese da admissibilidade dos efeitos prospectivos em controle difuso e os que rejeitaram tal ponderação. Somente informa a participação e realização de voto da Presidente da Corte, Min. Ellen Gracie, para a resolução do conflito. 
GUANAES, Rafael Maia. É possível a modulação de efeitos nas decisões administrativas?. Revista Eletrônica Direito e Política, Programa de Pós-Graduação Stricto Sensu em Ciência Jurídica da UNIVALI, Itajaí, v.10, n.2, $1^{\circ}$ quadrimestre de 2015. Disponível em: www.univali.br/direitoepolitica - ISSN 1980-7791.

de alíquota zero com base em uma lei editada em 1999 que autorizava tal prática. No mérito, o STF decidiu no sentido de que tal lei não estaria abarcada pelo art. 153, $\S 30$, II - princípio da não cumulatividade do IPI -, pois não abrangia hipótese em que o produto chega na indústria em alíquota zero.

Assim, o pedido de modulação de efeitos no presente caso em verdade se resumia em declarar o direito ao crédito de determinado contribuinte estendido até determinada data, tanto que foi pleiteado pela via do mandado de segurança e não à (in)constitucionalidade de uma lei, como bem ressalta o Min. Marco Aurélio no inteiro teor de seu voto sobre a questão de ordem suscitada, o fato de que determinados contribuintes sobre a mesma controvérsia requereram face ao Poder Judicante pelo fundamento da carga tributária extravagante a aplicação do art. 153, $\S 30$, II a tais hipóteses, comportamento esse que pela ótica deste Ministro seria aí sim um campo propício para uma melhor análise sobre a possibilidade jurídica dos efeitos pro futuro em sede de controle difuso.

Por motivos dessa natureza, dentre outros, causa surpresa decisão do Superior Tribunal de Justiça no sentido de negar a modulação temporal em julgado de sua competência sob o argumento de que tal fenômeno somente pode acontecer nas hipóteses de declaração de inconstitucionalidade nos exatos moldes do artigo 27 da Lei 9868/99, sob pena de usurpação da atividade legislativa ${ }^{27}$.

Isso porque há muito tempo o STF em seus julgamentos declara a inconstitucionalidade de leis e atos normativos não observando a incidência da sanção de nulidade em sua plenitude. Vale asseverar que essa mitigação dos efeitos não vem a ser utilizada como regra nesses casos, realizando os Ministros da Corte com muita diligência uma criteriosa adequação para a utilização desse poderoso instrumento decisório.

Pode-se compreender essa assertiva por exemplo no estudo de sua jurisprudência anterior à Constituição de 1988, em julgado relatado pelo Ministro Rodrigues Alckmin, que já consagrava o que o Professor Gustavo Binenbojm

27 BRASIL, STJ, AgRg nos EDcl no Agravo de Instrumento no 983549/DF, Rel. Min. Mauro Campbell Marques, $2^{\text {a }}$ Turma, publicado in DJ de 13/05/2009 
GUANAES, Rafael Maia. É possível a modulação de efeitos nas decisões administrativas?. Revista Eletrônica Direito e Política, Programa de Pós-Graduação Stricto Sensu em Ciência Jurídica da UNIVALI, Itajaí, v.10, n.2, $1^{\circ}$ quadrimestre de 2015. Disponível em: www.univali.br/direitoepolitica - ISSN 1980-7791.

denomina com muita propriedade "imposições de experiência à lógica jurídica" o fenômeno da flexibilização dos efeitos temporais da declaração de inconstitucionalidade ${ }^{28}$ :

Assim, conforme declarou o Supremo Tribunal no acórdão referido, embora a suspensão da vigência da lei por inconstitucionalidade torne sem efeito todos os atos praticados sob o império da lei inconstitucional, no caso de decisão transitada em julgado é necessária ação rescisória para tornar sem efeito a eficácia da coisa julgada.

Os juristas assim como os próprios cidadãos do século XXI não admitem mais que agentes do Estado, seja de qual esfera for - executiva, legislativa ou judiciária - , não viabilizem a efetividade dos direitos fundamentais e a continuidade evolutiva do Estado Democrático de Direito com base em falta de amparo legal. Essa decisão do STJ que negou a limitação dos efeitos vai na contramão do pensamento jurídico contemporâneo, hoje regido pelo póspositivismo, baseado em uma reaproximação entre Ética e Direito e nas idéias de justiça e legitimidade ${ }^{29}$.

Reforçando a questão da desnecessidade da lei para se aplicar a limitação de efeitos para as decisões provenientes da Administração temos na obra de Peter Häberle Hermenêutica Constitucional - A sociedade aberta dos intérpretes da Constituição: Contribuição para a interpretação pluralista e "procedimental" da Constituição - relevantes teses favoráveis a esse entendimento. Iniciando os postulados do instituto jurídico da realidade constitucional, o autor assevera que a interpretação da Constituição não se centra somente na interpretação constitucional dos juízes, em seu veículo oficial. Todo aquele que vive a Constituição seria seu legítimo intérprete, ainda que potencialmente.

Ampliando assim o círculo de intérpretes da Constituição se depreende a proposta de democratização da interpretação constitucional, alterando assim de forma radical os métodos de interpretação da Constituição de um Estado.

28 BINENBOJM, Gustavo. A Nova Jurisdição Constitucional Brasileira, $1^{a}$ edição, Rio de Janeiro: Renovar, 2001, p. 180/181

${ }^{29}$ BARROSO, Luis Roberto. Fundamentos teóricos e filosóficos do novo constitucionalismo brasileiro (Pós-modernidade, teoria crítica e pós-positivismo) In Revista Diálogo Jurídico, Salvador, CAJ - Centro de Atualização Jurídica, v. 1, no 6, setembro de 2001, p. 19 
GUANAES, Rafael Maia. É possível a modulação de efeitos nas decisões administrativas?. Revista Eletrônica Direito e Política, Programa de Pós-Graduação Stricto Sensu em Ciência Jurídica da UNIVALI, Itajaí, v.10, n.2, $1^{\circ}$ quadrimestre de 2015. Disponível em: www.univali.br/direitoepolitica - ISSN 1980-7791.

Visando oferecer maior sistematicidade à sua tese, faz uma "apresentação sistemática dos participantes" da interpretação, momento no qual insere diversos grupos sociais neste grupo, dentre os quais se refere de forma expressa aos órgãos estatais, sendo assim sua tese plenamente cabível juridicamente à hipótese proposta de cabimento da modulação de efeitos às decisões administrativas, independentemente de autorização legal, por ser um dos principais responsáveis pelo processo de interpretação constitucional ${ }^{30}$ :

\section{Catálogo sistemático}

A tentativa de se fazer uma apresentação sistemática dos participantes da interpretação sugere o seguinte catálogo provisório:

(1) as funções estatais:

a) na decisão vinculante (da Corte Constitucional): decisão vinculante que é relativizada mediante o instituto do voto vencido;

b) nos órgãos estatais com poder de decisão vinculante, submetidos, todavia, a um processo de revisão: jurisdição, órgão legislativo (submetido a controle de consonância com objeto da atividade): órgão do Executivo, especialmente na (pré) formulação do interesse público;

\subsection{Técnica de modulação de efeitos como forma de salvaguardar a segurança jurídica nas decisões administrativas}

Ao iniciarmos o processo de justificação da técnica de restrição de efeitos da nulidade à seara administrativa, cumpre tratarmos, ainda que sobre uma análise perfunctória, sobre o princípio reconhecido ${ }^{31}$ de Direito Administrativo da autotutela. Este princípio basicamente vem a ser um dos mais importantes corolários da supremacia do interesse público nas ações administrativas, por

30 HÄBERLE, Peter. Hermenêutica Constitucional. A sociedade aberta de intérpretes da Constituição: contribuição para a interpretação pluralista e "procedimental" da Constituição, Traduzido por Gilmar Ferreira Mendes, Sergio Antonio Fabris Editor, Porto Alegre, reimpressão, 2002, p. 20

31 CARVAlHo, José dos Santos. Manual de Direito Administrativo. Rio de Janeiro, Ed. Lumen Júris, 14ª edição, p. 24 
GUANAES, Rafael Maia. É possível a modulação de efeitos nas decisões administrativas?. Revista Eletrônica Direito e Política, Programa de Pós-Graduação Stricto Sensu em Ciência Jurídica da UNIVALI, Itajaí, v.10, n.2, $1^{\circ}$ quadrimestre de 2015. Disponível em: www.univali.br/direitoepolitica - ISSN 1980-7791.

impor ao agente público o dever de agir em situações irregulares ora verificadas no exercício de suas funções, independentemente de provocação.

Analisando de forma mais apurada essa forma de atuação ex officio da Administração, reputamos como premissa de argumentação o fato de que esse agir administrativo pode ser realizado tanto na esfera preventiva como na repressiva como também de que pode recair sobre aspectos de legalidade, em que se verifica a realização de revisão de atos ilegais com base em desconformidade com o ordenamento jurídico.

Nesse diapasão, temos nessa atividade saneadora da Administração Pública uma nítida idéia de indisponibilidade dos interesses públicos, motivo esse que pode sem grande esforço interpretativo colocar essa indisponibilidade como mais um motivo ensejador da admissibilidade da aplicação da modulação de efeitos nas decisões tomadas pelo Administrador Público.

Para fins de delimitação do objeto de estudo do exercício da autotutela administrativa em atos nulos, não se examinará a hipótese de revogação do ato por parte da Administração, que além de possuir natureza completamente diversa da nulidade, já possui um arcabouço jurídico próprio na Lei 9.784/1999 (Lei do Processo Administrativo Federal), que enuncia regra importante sobre a retroatividade no momento de revogação do ato, em seu artigo $2{ }^{\circ}$, inciso XIII, in verbis: "interpretação de norma administrativa da forma que melhor garanta o atendimento do fim público a que se dirige, vedada aplicação retroativa de nova interpretação".

Essa regra sobre interpretação de normas foi confirmada pelo Superior Tribunal de Justiça em tema da seara tributária, quando se posicionou pela não retroatividade ao artigo $3^{\circ}$ da Lei Complementar 118/2005, que interpretava a extinção do crédito tributário aos tributos lançados por homologação que deveriam ter como início do prazo prescricional o momento do pagamento antecipado, mesmo com esse Tribunal anteriormente já ter pacificado sua jurisprudência no sentido de que esse prazo somente se iniciaria quando se iniciaria apenas ou por expressa homologação do Fisco ou decorridos cinco anos do respectivo fato gerador (homologação tácita). 
GUANAES, Rafael Maia. É possível a modulação de efeitos nas decisões administrativas?. Revista Eletrônica Direito e Política, Programa de Pós-Graduação Stricto Sensu em Ciência Jurídica da UNIVALI, Itajaí, v.10, n.2, 10 quadrimestre de 2015. Disponível em: www.univali.br/direitoepolitica - ISSN 1980-7791.

Outra ponderação delimitadora reside no fato de que não se irá versar sobre efeitos de decisões administrativas decorrentes de atos anuláveis ${ }^{32}$, tendo em vista que se trata de atos válidos, somente podendo ser declarados como nulos por meio de decisão judicial expressa nesse sentido. Deve neste caso o próprio Poder Judicante, se provocado pelas partes, definir a extensão de seus efeitos.

A autotutela administrativa surge de forma expressa pelo mundo jurídico na tradicional e sempre oportuna controvérsia sobre o verbete 473 da Súmula de Jurisprudência Dominante do STF, que versa sobre o princípio informativo do direito administrativo da autotutela, que está de acordo com a jurisprudência e doutrina de seu tempo, porém nos dias de hoje ela merece uma releitura para se adequar à forte influência dos princípios de natureza ética como a transparência, moralidade administrativa e a proporcionalidade em sentido estrito, sendo necessária sua revisão.

Destarte, esse pedido de revisão já existe por parte da Ministra do Excelso Pretório Cármen Lucia, conforme visto pela comunidade jurídica no Informativo 641 daquela Corte quando informa o resultado do julgamento no RE 594296/MG, da relatoria do Ministro Dias Toffoli, porém de natureza diversa do objeto deste estudo, no sentido de que seja acrescentada a expressão "garantidos, em todos os casos, o devido processo legal administrativo e a apreciação judicial", para que o verbete da Súmula não seja utilizado para fundamentar decisões administrativas eivadas de vícios. Se faz necessário que a Corte Suprema constitucionalize tal verbete, para trazê-lo à realidade constitucional, dando ao menos a faculdade à Administração de regulamentar as situações jurídicas em que há o enfrentamento de respeito a direitos adquiridos em face de atos administrativos nulos de pleno direito quando declarados pelo ente público.

A impossibilidade na via administrativa de se mitigar o dogma da sanção de nulidade traz como inevitável resultado o assoberbamento de demandas frente

\footnotetext{
32 Reconhece-se como uma das grandes controvérsias dentro do tema dos atos administrativos, estando ciente de doutrinadores de extrema relevância do Direito Administrativo como o saudoso Hely Lopes Meirelles e Diógenes Gasparini rechaçavam a própria existência de atos anuláveis, adotando a teoria monista da teoria das nulidades.
} 
GUANAES, Rafael Maia. É possível a modulação de efeitos nas decisões administrativas?. Revista Eletrônica Direito e Política, Programa de Pós-Graduação Stricto Sensu em Ciência Jurídica da UNIVALI, Itajaí, v.10, n.2, $1^{\circ}$ quadrimestre de 2015. Disponível em: www.univali.br/direitoepolitica - ISSN 1980-7791.

ao Poder Judiciário visando a preservação de direitos adquiridos em face de atos administrativos nulos sem qualquer necessidade prática, pois poderiam ser praticados pela Administração por meio da técnica de modulação de efeitos de decisões, incorporado de forma expressa no ordenamento jurídico brasileiro pelo art. 27 da Lei 9868/99 nas decisões proferidas pelo Supremo Tribunal Federal quando este órgão atua como o competente para realizar o controle de constitucionalidade de leis.

Um dos principais motivos do uso de tal técnica está na característica da decisão judicial de ser dotada de força de lei entre as partes ${ }^{33}$, em virtude de sua intrínseca natureza substitutiva de suas vontades, que no controle de constitucionalidade toma dimensões extraprocessuais, tendo por força constitucional efeitos contra todos e efeito vinculante perante os demais órgãos do Poder Judiciário e a Administração Pública nas esferas federal, estadual e municipal.

O Executivo também possui poder decisório que invade situações jurídicas alheias, especialmente na condução das políticas públicas, e pela grande impactação nas situações jurídicas que criam, as decisões administrativas derivadas da condução de políticas públicas, até pela legitimidade popular intrínseca aos representantes do Poder Executivo, merecem um tratamento jurídico ao menos similar do que se afere nas decisões jurisdicionais possíveis de modulação.

Assim, o que se defende não seria a possibilidade de qualquer agente público a faculdade de ponderar a modulação de efeitos decorrentes de declaração de nulidade, atribuindo-se tal prerrogativa somente aos responsáveis pela condução de políticas públicas estatais, aos representantes eleitos pelo voto popular, posto que somente desta forma a segurança jurídica e o princípio da igualdade não restariam violados em seu conteúdo essencial. A tais agentes caberia a bem da verdade a prerrogativa de regulamentar o exercício desta faculdade, sendo tais

33 BRASIL, Código de Processo Civil. "Art. 468 - A sentença, que julgar total ou parcialmente a lide, tem força de lei nos limites da lide e das questões decididas." 
GUANAES, Rafael Maia. É possível a modulação de efeitos nas decisões administrativas?. Revista Eletrônica Direito e Política, Programa de Pós-Graduação Stricto Sensu em Ciência Jurídica da UNIVALI, Itajaí, v.10, n.2, $1^{\circ}$ quadrimestre de 2015. Disponível em: www.univali.br/direitoepolitica - ISSN 1980-7791.

atos normativos dotados de obrigatoriedade que vincularia a Administração quando esta tiver que enfrentar o tema alvo da modulação.

E como o administrador se encontra impedido de exercer instrumentos que viabilize a preservação de direitos mesmo em se tratando de atos nulos de pleno direito, se assoberba de forma desnecessária as distribuições dos foros judiciários, por algumas vezes com milhões de demandas ajuizadas em todo o País em face da Administração Pública, questões essas que até depois de decididas de forma definitiva em posição contrária ao entendimento do administrador se resolve fazer composições e acordos com o próprio Judiciário sobre a uniformização de tratamento entre as massas populacionais envolvidas no conflito, não assumindo o papel de vanguarda afeto à essa função estatal dentro da tripartição de poderes.

Porém o desgaste frente aos cidadãos - destinatários de toda a ação administrativa - e à opinião pública fazem trazer à tona uma triste pecha de que o administrador público não possui qualquer relação de zelo com o cidadão, pois cuida apenas de um interesse meramente governamental - transitório, precário, movido muitas vezes por circunstâncias alheias à eticidade e aos interesses da coletividade.

Porém, mesmo diante de um quadro completamente desfavorável, recentemente começa-se a perceber uma mudança de conduta por parte da Administração no que toca ao reconhecimento de direitos por parte de uma coletividade que está vinculada com o ente público por uma relação jurídica base. É o que ocorre com os grandes processos de ações revisionais previdenciárias do RGPS, a cargo do Instituto Nacional do Seguro Social (INSS). São demandas que se originam de diversas regiões do País ajuizadas na Justiça Federal por milhares de segurados. No caso recente da revisão de teto dos benefícios decorrentes de aumentos trazidos pelas Emendas Constitucionais 20/1998 e 41/2003, o próprio INSS internamente procedeu a essa revisão com base em um acordo feito em ação coletiva ajuizada pelo Ministério Público Federal em São Paulo. Essa decisão 
GUANAES, Rafael Maia. É possível a modulação de efeitos nas decisões administrativas?. Revista Eletrônica Direito e Política, Programa de Pós-Graduação Stricto Sensu em Ciência Jurídica da UNIVALI, Itajaí, v.10, n.2, $1^{\circ}$ quadrimestre de 2015. Disponível em: www.univali.br/direitoepolitica - ISSN 1980-7791.

administrativa revisou aproximadamente 120 mil benefícios e teve o impacto mensal de $\mathrm{R} \$ 28.000 .000,00$ (vinte e oito milhões de reais) ${ }^{34}$.

Contudo, reforça-se que não houve uma iniciativa espontânea por parte do ente público no reconhecimento do direito, atuando por força de um acordo em processo coletivo. Por tal motivo, o Judiciário refuta condições desse acordo quando o segurado ajuíza demanda individual. Uma situação emblemática que ilustra a hipótese cinge-se no fato de que uma das condições firmadas foi a de pagar de forma parcelada os atrasados dessa revisão na maioria dos casos, conforme o critério de idade do segurado. Em demandas individuais, os segurados conseguem esse pagamento de atrasados de forma imediata e em única parcela, sem qualquer critério definidor para justificar essa posição de preferência frente aos demais segurados beneficiados pelo acordo.

Diante deste quadro, o único caminho a ser trilhado pelo Executivo dentro do Estado Democrático de Direito deve ser o pautado pelos parâmetros de natureza ética, aptos a nortear a atividade administrativa no campo deliberativo para dotá-la enfim da tão almejada legitimidade democrática para se tornar o fenômeno que Häberle denomina de "forças produtivas de interpretação"35, ou seja, que seja um dos responsáveis, ainda que potencialmente, pela interpretação constitucional.

Em verdade poderíamos dotar o agente público executor das políticas públicas com o dever administrativo de proteger os direitos adquiridos dos administrados, com base no princípio de autotutela. Não há mais nos dias atuais qualquer vedação a tal assertiva, pois a hermenêutica constitucional aplicada em terra brasilis adere claramente aos conceitos de Peter Häberle de sociedade aberta, não fazendo parte da realidade constitucional apenas a interpretação dos juízes em procedimentos formalizados, mas sim composto por elementos das teorias

34 Obtido via internet. http://www.previdencia.gov.br/revisao-do-teto-previdenciario/. 12/02/2013, 23:30

35 HÄBERLE, Peter. Hermenêutica Constitucional. A sociedade aberta de intérpretes da Constituição: contribuição para a interpretação pluralista e "procedimental" da Constituição, Traduzido por Gilmar Ferreira Mendes, Sergio Antonio Fabris Editor, Porto Alegre, reimpressão, 2002, p. 140 
GUANAES, Rafael Maia. É possível a modulação de efeitos nas decisões administrativas?. Revista Eletrônica Direito e Política, Programa de Pós-Graduação Stricto Sensu em Ciência Jurídica da UNIVALI, Itajaí, v.10, n.2, $1^{\circ}$ quadrimestre de 2015. Disponível em: www.univali.br/direitoepolitica - ISSN 1980-7791.

jurídicas funcionais e das ciências sociais, ampliando assim de forma significativa o campo de agentes conformadores dessa sociedade aberta de intérpretes ${ }^{36}$.

E a inserção dessa realidade no processo de interpretação levou a uma severa mudança no método de aplicação do Direito, admitindo-se nesse processo o acesso às forças políticas de poder, aproximando no plano teórico a teoria da constituição da ciência política. Mais uma vez a inestimável contribuição de Häberle se faz presente, quando concebe a teoria constitucional como uma ciência da experiência que deve estar em condições de explicitar os grupos concretos de pessoas a participar e os fatores que constituem um espaço público propício para se delinear as formas de concepção e desenvolvimento da law in public action ${ }^{37}$.

Outrossim, a abertura oferecida ao administrador no sentido de dar eficácia retroativa ou prospectiva de suas decisões vai de encontro às mais modernas técnicas de metodologia do direito acolhidas pela comunidade jurídica. Isso porque tal prática estimula um maior dinamismo na atividade administrativa, visto que com o uso desta técnica o gestor público pode tomar mais decisões, pois pela concepção tradicional por muitas oportunidades o administrador deixa de decidir sobre determinado caso concreto trazido com temor dos eventuais efeitos retroativos dessa decisão, estimulando assim a omissão administrativa, inadmissível dentro de um Estado que se propõe a cumprir diversas demandas no campo social-econômico.

\footnotetext{
${ }^{36}$ HÄBERLE, Peter. Hermenêutica Constitucional. A sociedade aberta de intérpretes da Constituição: contribuição para a interpretação pluralista e "procedimental" da Constituição, Traduzido por Gilmar Ferreira Mendes, Sergio Antonio Fabris Editor, Porto Alegre, reimpressão, 2002, p. 12-14

37 HÄBERLE, Peter. Hermenêutica Constitucional. A sociedade aberta de intérpretes da Constituição: contribuição para a interpretação pluralista e "procedimental" da Constituição, Traduzido por Gilmar Ferreira Mendes, Sergio Antonio Fabris Editor, Porto Alegre, reimpressão, 2002, p. 17 e ss.
} 
GUANAES, Rafael Maia. É possível a modulação de efeitos nas decisões administrativas?. Revista Eletrônica Direito e Política, Programa de Pós-Graduação Stricto Sensu em Ciência Jurídica da UNIVALI, Itajaí, v.10, n.2, $1^{\circ}$ quadrimestre de 2015. Disponível em: www.univali.br/direitoepolitica - ISSN 1980-7791.

\section{CONSIDERAÇÕES FINAIS}

Portanto, reputamos como plenamente aceitável e adequado ao atendimento das demandas sociais dentro do Estado Democrático de Direito o compromisso da Administração Pública com os efeitos de suas decisões no mundo fático, estando em consonância com o pensamento de vanguarda dos juristas preocupados com o aperfeiçoamento da democracia em solo brasileiro o dever com base no princípio da autotutela administrativa de o Administrador Público modular efeitos retroativos ou prospectivos de suas decisões.

A defesa dos direitos adquiridos dos cidadãos perante o Poder Público possui estatura de garantia de índole legal e constitucional, não sendo acreditável sequer a cogitação de uma harmônica convivência em sociedade sem garantias mínimas de estabilidade nas relações jurídicas instituídas perante o Poder Público. Esse inegável desequilíbrio existente nessas relações somando ao fato de termos adotado uma Constituição dirigente e compromissada com o bemestar social somente faz reforçar o componente ético nessas relações.

Vive-se atualmente tempos difíceis, em que o fenômeno da globalização dos setores de produção, que além do paradoxo dos incríveis avanços tecnológicos com o incremento da desigualdade - fenômeno conhecido pela sociologia contemporânea como "sociedade de risco"38 - trouxe uma multiplicidade de formas de interações humanas que alteraram de forma radical diversas facetas da relação entre Estado e Sociedade, aproximando a realidade constitucional à ideia de Peter Häberle de que a democracia é o domínio do cidadão, e não do povo como na lógica da soberania popular de Rousseau. Com efeito, a democracia do cidadão é a que se concebe a partir dos direitos fundamentais e não a de que o povo assume a titularidade do poder do monarca.

Assim, há de se resgatar a afirmação do constitucionalismo nas práticas administrativas e autorizar a inserção de técnicas modernas na formatação de suas decisões, tal como a modulação de efeitos, como forma de instrumentalizar

38 BARRETO, Vicente de Paulo. Para além dos Direitos Fundamentais, In Direitos Fundamentais \& Novos Direitos, org. por Renata Braga Klevenhusen, Rio de Janeiro: Lumen Juris, 2005, p. 148 
GUANAES, Rafael Maia. É possível a modulação de efeitos nas decisões administrativas?. Revista Eletrônica Direito e Política, Programa de Pós-Graduação Stricto Sensu em Ciência Jurídica da UNIVALI, Itajaí, v.10, n.2, $1^{\circ}$ quadrimestre de 2015. Disponível em: www.univali.br/direitoepolitica - ISSN 1980-7791.

o Executivo nos novos tempos que batem a porta e que certamente não esperarão muito tempo para que tenha que se inserir de forma mais eficiente no seu poder-dever de fomentador do Estado Democrático de Direito.

\section{REFERÊNCIAS DAS FONTES CITADAS}

AlLegretti, Umberto, Amministrazione Pubblica e Constituzione, Padova, CEDAM, 1996

ARISTÓTELES, Tratado de política, São Paulo, Publicações Europa-América, 1977

BARRETO, Vicente de Paulo. Para além dos Direitos Fundamentais, In Direitos Fundamentais \& Novos Direitos, org. por Renata Braga Klevenhusen, Rio de Janeiro: Lumen Juris, 2005

BARROSO, Luis Roberto. Fundamentos teóricos e filosóficos do novo constitucionalismo brasileiro (Pós-modernidade, teoria crítica e póspositivismo) In Revista Diálogo Jurídico, Salvador, CAJ - Centro de Atualização Jurídica, v. 1, n० 6, setembro de 2001

BERCOVICI, Gilberto, In Canotilho e a Constituição Dirigente, organizado por Jacinto Nelson de Miranda Coutinho, Rio de Janeiro, Renovar, 2005

Constituição e política: uma relação difícil. Publicação Lua Nova, no 61, CEDEC, Centro de Estudos de Cultura Contemporânea, São Paulo, 2004

BINENBOJM, Gustavo. A Nova Jurisdição Constitucional Brasileira, $1^{a}$ edição, Rio de Janeiro: Renovar, 2001

BONAVIDES, Paulo. Curso de Direito Constitucional, São Paulo ,Ed. Malheiros, 2007

BUZAID, Alfredo. Da Ação Direta de Inconstitucionalidade no Direito Brasileiro. São Paulo, Ed. Saraiva 
GUANAES, Rafael Maia. É possível a modulação de efeitos nas decisões administrativas?. Revista Eletrônica Direito e Política, Programa de Pós-Graduação Stricto Sensu em Ciência Jurídica da UNIVALI, Itajaí, v.10, n.2, $1^{\circ}$ quadrimestre de 2015. Disponível em: www.univali.br/direitoepolitica - ISSN 1980-7791.

CANOTILHO, José Joaquim Gomes, In Canotilho e a Constituição Dirigente, organizado por Jacinto Nelson de Miranda Coutinho, Rio de Janeiro, Renovar, 2005

CAPPELLETTI, Mauro; GARTH, Bryant. Acesso à Justiça. Tradução de Ellen Gracie Northfleet. Porto Alegre: Sergio Antonio Fabris, 1988

CARVAlHo, José dos Santos. Manual de Direito Administrativo. Rio de Janeiro, Ed. Lumen Júris, 14a edição

GROSSI, Paolo. A formação do jurista e a exigência de um hodierno "repensamento" epistemológico. Obtida via internet. ojs.c3sl.ufpr.br/ojs2/index.php/direito/article/download/1731/1431. em $15 / 03 / 2010$ às $02: 30$

HABERMAS, Jürgen, Between Facts and Norms. Contribution to a Discurse Theory of Law and Democracy, tradução de William Rehg, Cambridge, Massachussets Institute of Tecnology Press, 1996

HÄBERLE, Peter. Hermenêutica Constitucional. A sociedade aberta de intérpretes da Constituição: contribuição para a interpretação pluralista e "procedimental" da Constituição, Traduzido por Gilmar Ferreira Mendes, Sergio Antonio Fabris Editor, Porto Alegre, reimpressão, 2002

Teoria de la Constitucion como ciência de la cultura. Tradução de Emilio Mikunda. Madrid, Tecnos, 2000

LASSALE, Ferdinand. A essência da Constituição. Rio de Janeiro, Ed. Líber Juris, 1998

LEAL, Rogério Gesta, O Estado-Juiz na Democracia Contemporânea, Porto Alegre, Livraria do Advogado, 2007

LEAL, Victor Nunes, Coronelismo, enxada e voto: o município e o sistema representativo na Brasil, São Paulo, Alfa Omega, 1975 
GUANAES, Rafael Maia. É possível a modulação de efeitos nas decisões administrativas?. Revista Eletrônica Direito e Política, Programa de Pós-Graduação Stricto Sensu em Ciência Jurídica da UNIVALI, Itajaí, v.10, n.2, $1^{\circ}$ quadrimestre de 2015. Disponível em: www.univali.br/direitoepolitica - ISSN 1980-7791.

MENDES, Gilmar Ferreira, COELHO, Inocêncio Mártires e BRANCO, Paulo, Curso de Direito Constitucional, 3a edição, São Paulo, Saraiva, 2008

MONTESQUIEU, Charles Louis de Secondat, Baron de la. O Espírito das Leis, Trad. Fernando Henrique Cardoso e Leôncio Martins Rodrigues, São Paulo, Abril Cultural, Livro II, 1979

MOREIRA NETO, Diogo de Figueiredo, Mutações de Direito Administrativo, Rio de Janeiro, Renovar, 2001

SANTOS, Moacyr Amaral. Contra o processo autoritário. Revista da Faculdade de Direito. São Paulo: USP, a. 54, n. 2, 1959. Obtido via Internet. www.planalto.gov.br/ccivil_03/revista/Rev_38/panteao.htm, em 28/04/2010, às $02: 10$

STRECK, Lênio Luiz, O Papel da Jurisdição Constitucional na realização dos direitos sociais-fundamentais, In Direitos Fundamentais sociais: Estudos de Direito Constitucional, Internacional e Comparado, Renovar, 2003 ., In Direitos Fundamentais e Novos Direitos, $2^{a}$ série, Rio de Janeiro, Lumen Juris, 2006

A Nova Perspectiva do Supremo Tribunal Federal sobre o controle difuso: Mutação constitucional e limites de legitimidade da Jurisdição. Obtida via internet www.mundojuridico.adv.br em 22/05/2010, ás 22:00

VERDÚ, Pablo Lucas, O sentimento constitucional, Rio de Janeiro, Editora Forense, $1^{\text {a }}$ edição, 2004

Submetido em: Janeiro/2015

Aprovado em: Março/2015 